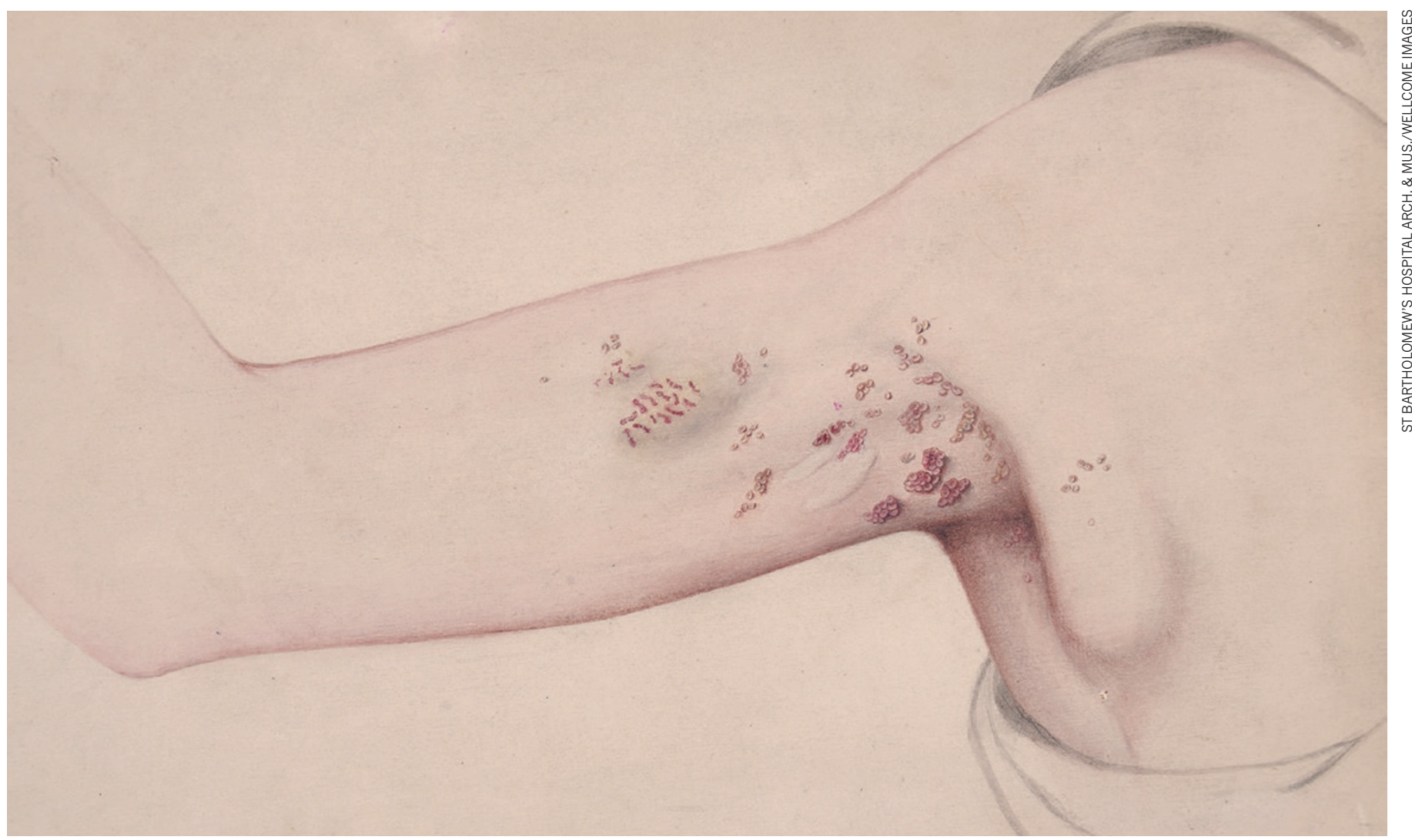

\title{
When the body betrays
}

\section{Tilli Tansey surveys a magisterial, historically rich biography of autoimmunity .}

A terrifying incident opens Intolerant Bodies. In 1981, novelist Joseph Heller became paralysed within a few hours by the autoimmune disease Guillain-Barré syndrome. In this horrific physiological own goal echoing the catch-22 of his classic book, Heller's immune system turned on his peripheral nervous system.

It has been calculated that in any population, $5-10 \%$ of people - a large proportion of them women - will at some point have an autoimmune disease. Intolerant Bodies, by the medically trained historian Warwick Anderson and clinical immunologist Ian Mackay, draws on medical, scientific, historical and literary sources to highlight four such conditions: type 1 diabetes, rheumatoid arthritis, systemic lupus erythematosus and multiple sclerosis.

The term autoimmune first appeared in 1951, and autoimmunity in 1957, although neither was then - or now - universally accepted. Some immunologists continue to prefer 'autoallergy'; the late Robin Coombs, inventor of the first specific test for red-cell

antibodies, declared that he would "go down fighting" in his opposition to 'autoimmune'.

Mackay and Anderson focus less on the heyday of autoimmunity in the past few decades than on its 'prehistory' and emergence as a defined field of medical research and practice. Earlynineteenth-century studies of fevers led to

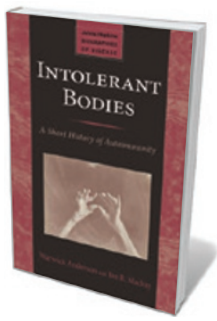

Intolerant Bodies: A Short History of Autoimmunity WARWICK ANDERSON AND IAN R. MACKAY Johns Hopkins University Press: 2014 the recognition that the body's own physiological responses could be harmful, and germ theory later that century spurred knowledge of the body's defence mechanisms. Medical luminaries such as Robert Koch and Joseph Lister struggled to understand basic mechanisms and isolate causative agents. In the 1880 s, the Russian biologist Élie Metchnikoff argued that circulating cells, the phagocytes, digested invading cells. In the first half of the twentieth century, in public-health labs and early pharmaceutical companies, the development of serotherapy - treating infectious diseases such as diphtheria by injecting serum raised in an immunized animal - stimulated much research on the immune system.

The authors emphasize how after the Second World War, an increase in government and private funding led to the expansion of research laboratories, including Henry Kunkel's at the Rockefeller Institute in New York City, Macfarlane Burnet's at the Walter and Eliza Hall Institute in Melbourne, Australia, and those at industrial concerns such as pharmaceutical giant Merck. Researchers developed tools, techniques and languages based on cellular and molecular approaches. In Britain, Peter Medawar unravelled the mechanisms of rejection after tissue transplantation. In New York City, Jules Freund demonstrated that an emulsion of paraffin oil and dead mycobacteria, the causative organisms of tuberculosis, enhanced and prolonged 
immune reactions in animal models of disease. Burnet, who shared a Nobel prize with Medawar in 1960, recognized Freund's contribution as key to the experimental study of autoimmunity. The subject was now high on the agenda of many biomedical scientists. Work on subsets of lymphocytes, humantissue antigens and the genetics of histocompatibility factors all contributed to the understanding of cellular mechanisms, and to devising diagnostic and therapeutic strategies for an array of disorders.

But Intolerant Bodies is more than a history of scientific concepts, clinical practices and experimental activities. It explores fundamental questions such as 'What is self?' - how and why the body's sophisticated defence mechanisms fail to recognize its cells and tissues and start to destroy them. The authors draw on immunological, philosophical, psychological and religious literature for this intriguing discussion. They mine thoughts from the likes of philosopher Jacques Derrida and anthropologist David Napier for their reflections on the definitions, boundaries and limitations of self.

Furthermore, Anderson and Mackay reveal an expert understanding of how to use lived experience' to bring a biography of disease to life. Personal accounts demonstrate how, as theories about the causes of inexplicable chronic and debilitating diseases abounded, the variety of treatments devised to alleviate or 'cure' them expanded. The nineteenth-century German poet Heinrich Heine was treated with leeches, sulphur baths and morphine, but these did little for an aggressive neurological complaint that the authors suggest was multiple sclerosis. And in 1957, US novelist Flannery O'Connor, who had lupus, wrote to a friend, "Every time something new is invented I get in on the ground floor with it. There have been fine improvements in the medicine". But steroids also destroyed her bones, a therapeutic stalemate that made her final years miserable. Particularly harrowing is the case of English diarist W. N. P. Barbellion (the pen name of Bruce Frederick Cummings), author of the 1919 Journal of a Disappointed Man. Barbellion, diagnosed with multiple sclerosis in his twenties, began to hoard laudanum and to keep a pistol close by. The disease killed him less than five years after diagnosis.

Unlike many biographies, Intolerant Bodies has no neat ending. With more than 80 conditions now considered to be autoimmune, diagnosis remains irregular and treatments unsatisfactory. Although more and more is understood about mechanisms, the causative stimuli are still unknown. The history of autoimmunity is far from over.

Tilli Tansey is professor of the history of modern medical sciences at Queen Mary, University of London.

e-mail:t.tansey@qmul.ac.uk

\section{Books in brief}

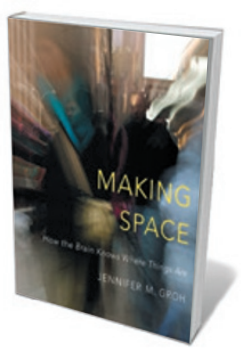

Making Space: How the Brain Knows Where Things Are

Jennifer M. Groh BELKNAP (2014)

The timing is spot-on for this study of the brain's navigational system, with a Nobel prize awarded to John O'Keefe, May-Britt Moser and Edvard Moser this month for their research in the field (see Nature 514, 154-157; 2014). Neuroscientist Jennifer Groh deftly elucidates the mental computations that allow understanding of location and boundaries, interweaving well-judged snippets of history. The mechanisms, such as the brain's updates on eye movements, are fascinating - as is Groh's revelation that neurons can "do double duty" in tasks such as spatial navigation and memory.

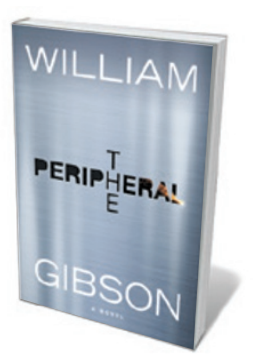

The Peripheral: A Novel

William Gibson PUTNAM AdULT (2014)

With Neuromancer (Ace, 1984), which predicted the rise of the Internet, science-fiction writer William Gibson revealed his nose for near-future science and for seeing, as he puts it, a future already here but not "evenly distributed". He harnesses that ability anew for this techno-thriller. From plastic in the oceans to three-dimensional printing, today's concerns are beautifully repurposed as tomorrow's background. But for Gibson, technological change is just a different route to the same problems: his protagonists, who wield the humanoid-telepresence 'peripherals', are socially marginalized.

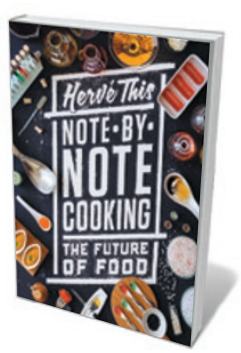

Note-by-Note Cooking: The Future of Food

Hervé This (transl. M. B. DeBevoise) COLUMBIA UnIVERSITY PRESS (2014) Molecular cooking, that scientific wonderland of filter pumps and rotary evaporators, has evolved. The new revolution, proclaims physical chemist Hervé This, is "note-by-note cooking" — the orchestration of pure molecular compounds. Amid the dollops of theory are practical examples, such as chef Pierre Gagnaire's glucose "péligot" caramels (exemplars of contrasting consistency), and lists of compounds including the mushroom-scented 1-octen-3-ol. Recipes are scant, although Effervescence, a cocktail involving Syrah grape polyphenols and ethanol, sounds toast-worthy.

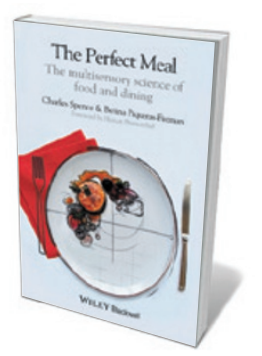

The Perfect Meal: The Multisensory Science of Food and Dining Charles Spence and Betina Piqueras-Fiszman WILEY (2014)

Anyone who thoughtlessly masticates their way through a meal is missing something extraordinary. So might opine experimental psychologists Charles Spence and Betina Piqueras-Fiszman, who have mined neuroscience and behavioural economics for this study of the social, sensory and psychological factors that optimize the pleasures of the table. Their exhaustive analyses of everything from plate size to flavour incongruities are laced with details such as cutlery's evolution from Victorian marrow scoops and chocolate muddlers to today's textured spoons and "aromatic forks".

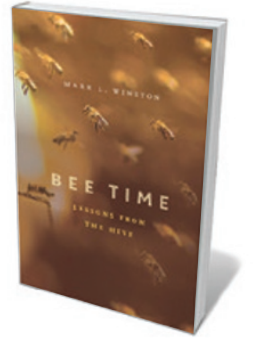

\section{Bee Time: Lessons from the Hive}

Mark L. Winston HARVARD UNIVERSITY PRESS (2014)

From the whirr of wings to the whiff of honey, the "full-body experience" of working in apiaries has, for biologist Mark Winston, sparked insights into humanity's relationship with nature. In this personal and scientific journey into the history we share with bees, he ranges over neonicotinoid pesticides and colony collapse, the control of African 'killer' bees and more. The charismatic social insects emerge as both icons of societal cohesion and symbols of nature's paradoxically mingled power and fragility. Barbara Kiser 